\title{
QUESTÕES TEÓRICAS E METODOLÓGICAS PARA OS ESTUDOS DE POLÍTICAS PÚBLICAS DE LAZER: ALGUNS SUBSÍDIOS
}

\author{
Recebido em: 13/02/2010 \\ Aceito em: 10/06/2010 \\ Flávia da Cruz Santos ${ }^{1}$ \\ UNICAMP \\ Campinas - SP - Brasil
}

RESUMO: Diante do atual momento do desenvolvimento alcançado pelos estudos de políticas públicas de lazer, este texto intenciona apontar as concepções teóricas e metodológicas contemporâneas de Bo Rothstein (1998) e Michael Mann (1991, 1993) sobre o social e o político como possibilidades teóricas e metodológicas para repensarmos tais estudos. Rothstein (1998) nos traz o debate sobre as concepções normativas das políticas, no que se refere aos valores, às concepções de justiça e às normas sociais, e apresenta sua proposta metodológica de confronto da teoria com a empiria. E Mann (1991, 1993) constrói a teoria das fontes do poder social, na qual aponta a existência de quatro fontes de poder, que se sobrepõem e interceptam umas às outras nas sociedades. Além disso, ele nos apresenta uma proposta metodológica que se aproxima da proposta apresentada por Rothstein (1998).

PALAVRAS-CHAVE: Atividades de Lazer. Políticas Públicas. Métodos.

\section{THEORETICAL AND METHODOLOGICAL QUESTIONS FOR LEISURE PUBLIC POLICIES STUDIES: SOME SUBSIDIES}

ABSTRACT: In today's stage of development reached by the studies and research public policies of leisure, this paper intends to point out the theoretical and methodological concepts contemporary Bo Rothstein (1998) and Michael Mann (1991, 1993) on the social and political as theoretical and methodological possibilities for to rethink the leisure policies studies. Rothstein (1998) brings us to the debate on the concepts of regulatory policies with regard to values, the concepts of justice and social standards, and presents its proposed methodology for confrontation of theory and empiricism. And Mann $(1991,1993)$ builds a theory of sources of social power, which indicates the existence of four sources of power that overlap and intersect in societies. Moreover, it presents a methodology that approaches proposed by Rothstein (1998).

KEYWORDS: Leisure Activities. Public Policies. Methods.

\footnotetext{
${ }^{1}$ Licenciada e Bacharel em Educação Física pela Universidade Federal de Minas Gerais. Mestranda em Educação Física pela Universidade Estadual de Campinas.
} 
Segundo Rothstein (1998, p. 08), muito do que tem sido escrito a respeito de políticas públicas nos últimos vinte anos consiste em estudos de caso detalhados, focalizados na implementação de diferentes políticas isoladas, um tanto míopes e com limitadas ambições teóricas, o que não tem apresentado contribuições para uma teoria empírica do Estado. Tal afirmação - apesar de o autor provavelmente não saber - é uma descrição precisa dos estudos brasileiros de políticas públicas que tem o lazer como objeto.

As políticas públicas de lazer, como temática de estudos e pesquisas sistematizadas, ainda são novas no Brasil $^{2}$ e, apesar do crescente número de trabalhos publicados em torno de tal tema e dos esforços que estudiosos vem empreendendo na qualificação desses estudos - que têm sido expressos na realização de pesquisas que confrontam a teoria com a empiria, contribuindo, indubitavelmente, para o avanço dos estudos em torno de tal temática -, a sua produção bibliográfica é caracterizada por grande quantidade de relatos de experiência da implementação de projetos do setor esportivo em que o lazer está agregado. E, muitas vezes, esses estudos demonstram desconhecimento dos sentidos e significados políticos, institucionais e culturais das temáticas de que tratam e das relações da teoria e da análise políticas com a prática política. Esses estudos realizam um debate técnico sem associação com o debate político, como se fosse possível dissociar essas dimensões das políticas.

Essa situação traz consequências tanto para o campo teórico quanto para o prático, da gestão pública, e é a consequência, em grande medida, da formação acadêmica dos estudiosos que se debruçam sobre essa temática, pois grande parte desses

\footnotetext{
${ }^{2}$ Apesar da existência de estudos centrados na discussão das políticas públicas de lazer já nas décadas de 1920 e 1930 (PEIXOTO, 2007; GOMES; MELO, 2003), não houve regularidade desses trabalhos nas décadas seguintes, nem estudos sistematizados.
} 
estudos é realizada por professores ${ }^{3}$ de Educação Física que, em sua maioria, não possuíram sequer uma disciplina que tratasse de tal assunto em seus currículos de graduação. E é consequência também do desenvolvimento alcançado por esses estudos no atual momento histórico que se encontra articulado aos processos sociais e políticos que os engendram.

A intenção aqui não é a de meramente denunciar tal situação e evidenciar a necessidade de subvertê-la, mas, sim, de, à luz das concepções teóricas e metodológicas contemporâneas de Bo Rothstein (1998) e de Michael Mann (1991, 1993) sobre o social e o político, apontar algumas possibilidades para (re)pensá-la.

Esses autores apresentam contribuições aos estudos de políticas públicas em geral, contribuições teóricas e metodológicas. Rothstein (1998) traz à tona o debate, há muito esquecido, sobre as concepções normativas das políticas no que se refere aos valores, às concepções de justiça e às normas sociais. Apresenta também sua proposta metodológica de confronto da teoria com a empiria na construção dos estudos e das pesquisas de políticas públicas. Já Mann $(1991,1993)$ constrói a teoria das fontes do poder social, na qual aponta a existência de quatro fontes de poder que se sobrepõem e interceptam umas às outras nas sociedades. Ele questiona a possibilidade de uma única fonte de poder - a econômica, por exemplo - determinar sozinha a organização de uma sociedade. Além disso, Mann (1991, 1993) nos apresenta uma proposta metodológica que se aproxima da proposta apresentada por Rothstein (1998). Sugere que recorramos à teoria e à empiria, ziguezagueando entre uma e outra, pois só assim conseguiremos construir uma explicação plausível de como funciona uma sociedade, em um dado

\footnotetext{
${ }^{3}$ Apesar de utilizar apenas a palavra "professores", pois a língua portuguesa convencionou a prevalência do uso do gênero masculino quando houver mulheres e homens no mesmo grupo, estou me referindo também às professoras.
} 
momento. Desse modo, apresentarei, a seguir, alguns pontos do pensamento desses estudiosos que penso oferecer contribuições aos estudos das políticas de lazer.

\section{SUBSÍDIOS TEÓRICOS E METODOLÓGICOS POSSÍVEIS}

O modo como Rothstein (1998) formulou sua teoria política construtiva nos aponta um interessante caminho metodológico que pode contribuir para a construção de estudos de políticas de lazer mais consistentes, pois ele a formulou através do confronto da teoria normativa com estudos concretos de políticas públicas. Segundo tal autor, sem esse duplo foco - na teoria e na empiria - o debate sobre as políticas será abstrato, interminável e arbitrário.

No entanto, para que haja esse duplo foco nos estudos de políticas de lazer, seus estudiosos precisam, primeiro, se apropriar da discussão teórico-metodológica presente na Ciência Política, e mais especificamente no campo dos estudos de políticas públicas. Precisam compreender os elementos analíticos e os instrumentos heurísticos desse campo de conhecimento para, iluminados por eles, construírem seus estudos.

Há, de acordo com Rothstein (1998), a idéia de que é possível sair da teoria normativa direto para a teoria construtiva, sem que haja um estágio intermediário, o empírico, o que tem trazido consequências negativas para o estudo das políticas públicas. Já no campo de pesquisa de políticas públicas orientado empiricamente - que Rothstein (1998) chama de "empirical state theory" -, os pesquisadores avançam diretamente da análise empírica, baseada nos conceitos de racionalidade e de eficiência, para o oferecimento de recomendações para a ação, indicando qual o melhor método de implementação e enumerando os requisitos necessários para uma implementação de sucesso, sem levar em conta os aspectos normativos de cada caso. O que também cria 
problemas graves e pode levar a resultados catastróficos. Pois, considera-se assim que os problemas da implementação são apenas técnicos, desconsiderando os princípios morais fundamentais que estão em jogo quando pensamos em políticas de bem-estar e tornando desnecessária a busca de conceitos como justiça, democracia e igualdade.

Não existe uma forma melhor de organizar políticas públicas, um caminho único. E o uso de uma forma de organização inapropriada pode fazer com que a implementação de uma política falhe. Assim, para esse autor, a análise das políticas de bem-estar deve combinar os discursos normativo e empírico num dentro de um discurso construtivo. Se temos a intenção de entender o que o Estado pode fazer, devemos examinar não apenas sua capacidade de implementação, mas também sua tomada de decisão.

Aqui, Rothstein (1998) apresenta uma contribuição inestimável aos estudos de políticas de lazer, pois ele evidencia problemas muito comuns a esses estudos principalmente quando aborda o "empirical state theory" -, ao mesmo tempo em que aponta um possível caminho teórico-metodológico que nos possibilita colocar a teoria à prova, confrontando-a com a realidade concreta, interrogando-a e avaliando sua plausibilidade empírica. No entanto, mais uma vez, afirmo a necessidade primeira de nos apropriarmos da discussão analítico-conceitual da teoria e da análise política, sem a qual qualquer estudo de política pública será vazio, abstrato, pois será meramente técnico. Não estou, aqui, desprezando a dimensão técnica das políticas, mas apenas tentando evidenciar que ela não se separa da dimensão política e que, sozinha, não é capaz de nos oferecer os subsídios necessários para qualificarmos nossos estudos e nossa prática política - a gestão. 
Além disso, há ainda uma lacuna na construção de conhecimentos específicos ao lazer como direito social no Brasil. Rothstein (1998, p. 83) nos diz que um desenho de política que possua regras precisas é marcado por grande clareza: as decisões políticas são diretamente ligadas ao dever do Estado de empreender medidas específicas, e a ligação entre essas decisões e as precondições - o financiamento, por exemplo, - para sua implementação é evidente, o que não acontece com o lazer, pois não há regras institucionais, diretrizes, nem fonte de financiamento definidas na Constituição de 1988 para orientar a concretização do direito ao lazer. Ele está, assim, imprecisamente definido como direito social na Constituição brasileira de 1988. Há também ausência de um arcabouço legal infraconstitucional que trate especificamente do lazer e o defina mais precisamente.

Será essa imprecisão na definição política do lazer uma estratégia dos legisladores, como aponta Rothstein (1998, p. 83), quando afirma que a imprecisão presente nos textos legais não é acidental, mas, sim, uma tentativa de atender aos interesses conflitantes quando do desenho de uma política? Assim, a linguagem política tem sua lógica própria, manifestada no uso de termos genéricos, e um significado ambíguo (ROTHSTEIN, 1998, p. 83), o que corrobora a relevância de se estudar a origem das políticas - que já foi há muito tempo comprovada pelas Ciências Sociais mas que ainda está por se fazer nos estudos de políticas públicas de lazer. Segundo Siman (2005, p. 24), “só é possível apreender um fenômeno em sua totalidade, quando o estudo procura desvendar a origem da política demonstrando todo o processo de sua formação e evolução". E corrobora também a relevância de estudos históricos, verdadeiramente empíricos, que tratem da constituição do lazer como direito social no Brasil sem respostas prévias e determinismos; que sejam capazes de questionar o dito, 
que possuam sensibilidade para captar o silenciado, pois cada iniciativa do Estado na área social precisa ser compreendida em suas particularidades, considerando o contexto histórico e suas especificidades.

Um modelo analítico, seja qual for, direciona nossas escolhas quanto a quais os dados chave, quais os mais importantes e quais os marginais para compreender como funciona uma sociedade, ou algo dela, possui, portanto, algum critério de importância, ainda que não o explicite ${ }^{4}$. Muitos pesquisadores brasileiros do lazer tiveram e têm como foco da análise de seus estudos os detentores do poder econômico e/ou seus interesses. Assim, esses pesquisadores lançaram seu olhar apenas, e isso não é pouco, sobre um tipo de poder, o econômico, dando uma direção às interpretações da emergência do lazer na sociedade brasileira.

Nesse sentido, Michael Mann, em seu The sources of social power (1993), oferece importante contribuição para as pesquisas de políticas públicas de lazer, pois ele entende que o poder possui quatro fontes sociais, a ideológica, a econômica, a militar e a política, e que, em períodos históricos diferentes e em locais diferentes, cada uma delas, ou algumas delas, predominam, mas que as quatro fontes existem o tempo todo e determinam a estrutura das sociedades. Assim, ele concebe as sociedades como múltiplas redes de poder, que se sobrepõem e interceptam umas às outras. Esse é o modelo IEMP (ideological, economic, military and political).

Por exemplo, durante o século XVIII duas fontes sociais de poder, o econômico e o militar, foram predominantes na determinação da estrutura social ocidental. No século XIX, o poder militar perdeu força dentro do Estado Moderno e o capitalismo continuou a revolucionar a economia. A política e a economia se tornaram, então, as

\footnotetext{
${ }^{4}$ MANN, 1991.
} 
fontes de poder predominantes. O capitalismo e suas classes e o estado-nação tornaramse atores de poder decisivos nos tempos modernos (MANN, 1993).

As quatro fontes do poder social de Mann (1993) são tipos ideais, não existem em uma forma pura. Constituem redes socioespaciais de poder que se sobrepõem e se interceptam umas às outras, não são dimensões, níveis, nem fatores de uma única totalidade social. São organizações, meios institucionais de alcançar objetivos. As organizações de poder atual misturam essas quatro fontes, e todas elas são necessárias para a existência umas da outras. Por exemplo, uma organização econômica requer que alguns de seus membros partilhem de valores ideológicos e de normas e também necessita da defesa militar e da regulação do Estado. Assim, as organizações ideológica, política e militar ajudam a estruturar uma economia e vice-versa (MANN, 1993, p. 09).

Mann (1991, p. 14) nos diz também que as sociedades não são unitárias nem totalidades e, por isso, as relações sociais não podem se reduzir a alguma propriedade sistêmica do todo, como o modo de produção, o sistema cultural ou a organização militar. No entanto, ainda de acordo com Mann (1991, p. 14-15), a maior parte das teorias sociológicas toma o Estado como sua unidade total de análise. Isso foi dominante tanto na Sociologia quanto na História, no final do século XIX e no início do XX. Mas alguns sociólogos e historiadores modernos rechaçam o modelo do Estado nacional e utilizam o capitalismo ou o industrialismo como conceito-chave. No entanto, segundo Mann (1993), tanto os Estados quanto a economia constituem redes importantes de poder, mas são apenas dois dos quatro grandes tipos de redes de poder e, por isso, sozinhos não explicam o funcionamento de uma sociedade.

Cada uma das quatro fontes de poder social gera formas distintas de organizar o controle social (MANN, 1993, p. 07). Em diferentes lugares e momentos históricos, 
cada uma dessas fontes possui uma capacidade maior de organização que rege, durante algum tempo, a forma das sociedades em geral. Mas não existe um conceito-chave da sociedade, uma teoria pura e monocausal, pois uma única fonte de poder é raramente capaz de determinar sozinha toda a estrutura de uma sociedade, por isso a melhor forma de explicar as sociedades, sua estrutura e sua história é por meio das interrelações dessas quatro fontes do poder social (MANN, 1991, 1993).

Michael Mann (1991, 1993) oferece aqui importante contribuição para as pesquisas sobre políticas públicas de lazer, pois nos ajuda a perceber que não apenas os detentores do poder econômico e suas instituições precisam ser estudados para que se compreenda o lazer no Brasil, mas também outras fontes de poder que se encontram a essa entrelaçadas, além dos destituídos desses poderes, que, penso, são centrais para uma melhor compreensão desse fenômeno.

Esse autor afirma ainda que a Sociologia não pode se desenvolver sem um conhecimento da História, e que os historiadores não podem renunciar a teoria de como funcionam as sociedades, senão seriam prisioneiros dos lugares comuns de sua própria sociedade. Portanto, devemos ziguezaguear entre a teoria e a empiria até estabelecermos uma explicação plausível de como funciona uma dada sociedade em um dado momento, construindo, assim, uma teoria baseada na história (MANN, 1991, p. 10).

Assim, ambos os autores, Rothstein (1998) e Mann (1991, 1993), apontam um mesmo caminho metodológico, apesar da especificidade de cada um deles: o confronto da teoria com a empiria. Esse caminho pode ser decisivo, no atual momento, para a qualificação dos estudos e das pesquisas de políticas de lazer. 


\section{CONCEPÇÕES NORMATIVAS: MAIS SUBSÍDIOS TEÓRICOS E ALGUMAS APROXIMAÇÕES POSSÍVEIS}

Os direitos sociais, mais do que os outros dois conjuntos de direitos - civis e políticos -, são justificados pelo discurso moral, pelas concepções normativas. Igualdade e justiça orientam a definição de tais direitos em um país e, consequentemente, orientam as políticas sociais - que são as políticas que os tem como objeto. Historicamente, os direitos sociais estão associados à participação na riqueza social de um país. Como nos diz Carvalho (2007, p. 10), os direitos sociais permitem às sociedades reduzir os excessos de desigualdade produzidos pelo capitalismo e garantir um mínimo de bem-estar a todos, estão baseados na idéia da justiça social. Idéia essa que parte daquilo que o Estado deve fazer e não apenas do que ele pode fazer. E o que o Estado deve fazer é orientado pelas concepções normativas, no que se refere aos valores presentes em um país, às concepções de justiça e às normas sociais.

Desse modo, pode-se pensar que os direitos sociais não alcançarão seu objetivo se forem objeto de políticas seletivas, pois elas se destinam a alguns e não a todos, mas apenas se forem objeto de políticas universais, já que elas garantem tais direitos a todos os cidadãos. Mas, do mesmo modo, pode-se pensar que as políticas universais não garantirão os direitos sociais a todos, já que essas políticas garantem os mesmos direitos a todos, desconsiderando as diferentes especificidades e histórias dos sujeitos, o que as torna, também, políticas para alguns e não para todos.

Assim, a definição do alcance da política depende das normas sociais de um país, de uma concepção de justiça, e essas, por sua vez, são produto das condições institucionais em que são tomadas as decisões políticas, da maneira como as instituições estruturam o momento da tomada de decisão. Portanto, a forma da tomada de decisão 
exerce um papel decisivo, alterando a concepção que os indivíduos possuem de seus próprios interesses e, assim, suas ações. Existe uma lógica causal ligando as normas às instituições. Desse modo, instituições específicas dão origem a um conjunto particular de normas sociais, o que explica a existência de normas diferentes em sociedades diferentes, já que as instituições e suas formas de tomada de decisão variam nas distintas sociedades (ROTHSTEIN, 1998, p. 139).

As instituições políticas possuem uma ordem específica, uma forma que influencia as normas sociais e, assim, influencia a tomada de decisão dos cidadãos (ROTHSTEIN, 1998, p. 118). Sob certas condições institucionais, prevalece a racionalidade econômica; sob outras condições, as normas sociais é que prevalecerão. A questão então é: como funciona a relação entre as instituições políticas e a lógica da ação individual? (ROTHSTEIN, 1998, p. 120).

Rothstein (1998, p. 127) conclui que a lógica da ação humana é estratégica, pois o que nós fazemos - apoiamos um tipo de sistema de bem-estar social, por exemplo depende do que nós pensamos que os outros são e o que eles farão. Isso é um mapa mental e constitui as normas sociais. Essas normas são importantes para entendermos as variações no comportamento humano. No entanto, para entendê-las precisamos entender as instituições, pois são as condições institucionais que farão com que uma lógica de ação prevaleça sobre outras. As normas sociais, portanto, não são dadas estruturalmente pela cultura, história ou espírito mundial, mas pelo desenho político das instituições (ROTHSTEIN, 1988, p.129).

Então, agora, nossa questão é outra: qual é a relação entre a constituição de instituições do sistema político (mais especialmente aquelas envolvidas com a implementação de políticas sociais) e as normas de justiça, que são concepções 
normativas, prevalentes na sociedade? E como tais instituições podem ser formadas para promover a justiça para aqueles que fazem parte dela? A forma da tomada de decisão exerce um papel decisivo, alterando a concepção que os indivíduos possuem de seus próprios interesses e também suas ações.

Rothstein (1988, p.138) nos diz que, em certos momentos especiais da história, os atores políticos podem criar instituições, como, por exemplo, depois da queda do comunismo soviético na Europa Oriental, quando se tornou possível escrever novas constituições. Desse modo, os cidadãos possuem um papel de grande relevância na determinação das normas sociais que devem prevalecer na sociedade em que vivem, porque eles podem escolher o desenho de suas instituições políticas (ROTHSTEIN, 1988, p.135).

A sociedade brasileira viveu recentemente um momento histórico especial como o acima exemplificado por Rothstein (1988), quando do término dos governos militares, que possibilitou a construção de uma nova carta constitucional para o país. As normas sociais que prevaleciam na sociedade brasileira no momento da construção da Constituição de 1988 estavam pautadas pelas instituições existentes naquele momento histórico e, principalmente, pela forma de tomada de decisão daquelas instituições. A existência de um período de governo ditatorial e militar em que as instituições políticas eram antidemocráticas e injustas - de acordo com certa concepção de justiça - causou a demanda por instituições moralmente diferentes, com conteúdos normativos diferentes. Assim, as concepções morais dos cidadãos brasileiros levaram à construção de uma nova constituição, pautada pela participação, pela justiça e igualdade; levaram à ampliação dos direitos sociais, que possuem tais concepções neles mesmos. Assim, as concepções morais presentes na sociedade brasileira naquele momento tiveram 
importante papel na definição da Constituição de 1988 e na imagem que dela se construiu.

Tais concepções orientaram a definição dos direitos, principalmente dos direitos sociais, que foram ampliados, e fizeram com que a Constituição Brasileira de 1988 fosse considerada a "Constituição Cidadã". No entanto, demandar por justiça e igualdade não é o mesmo que demandar por um sistema de bem-estar social universal, por exemplo, pois justiça e igualdade são as concepções normativas da política e não a política propriamente dita. E nem sempre os cidadãos fazem a conexão dos conteúdos normativos com uma instituição ou com a dimensão prática de uma política. Assim, ao reivindicar por igualdade e justiça, os cidadãos podem obter como resultado instituições políticas e direitos os mais diversos.

Os direitos sociais são tidos como conquistas dos trabalhadores, como resultado da luta política entre capital e trabalho, que ocorre em cada país de forma diferente, são compreendidos como construções decorrentes de múltiplos conflitos e interesses ${ }^{5}$. São problemas sociais que deixam a condição de "estado de coisas" e se tornam problemas políticos através da mobilização e da luta políticas e são incorporados pelo Estado, passando a ser objeto de sua intervenção ${ }^{7}$. No entanto, nem todos os problemas sociais se constituem em problemas políticos ${ }^{8}$. Muitas questões sociais permanecem como “estado de coisas", enquanto outras se constituem em problemas políticos e são inseridos na agenda governamental.

\footnotetext{
5 Apoio-me nos trabalhos de LINHALES, (1988); MENICUCCI (2006); VERONEZ (2005); VIEIRA (1999). No entanto, não ignoro a existência de outras abordagens e entendimentos em torno da natureza e do significado dos direitos sociais. Ver a respeito em ARRETCHE (1995); COIMBRA (1987); FARIA (2007).

6 "Estado de coisas" é um conceito que se refere a uma situação que existe e incomoda grupos de pessoas, gerando insatisfações e, apesar disso, não mobiliza as autoridades governamentais, não se constituindo num problema político (RUA, 1998, p. 05).

${ }^{7}$ MENICUCCI (2006) e RUA (1998).

${ }^{8}$ COIMBRA (1987, p. 97); MENICUCCI (2006, p. 143-144); SIMAN, (2005, p. 47).
} 
O lazer, apesar de ser um direito social garantido constitucionalmente, não seguiu tal caminho, não foi reivindicado por movimentos sociais, apenas o tempo livre ${ }^{9}$ o foi, conforme nos dizem Melo e Alves Junior (2003, p. 29),

[...] um tempo livre maior surge não como concessão dos donos dos meios de produção, mas sim como conquista das organizações das classes trabalhadoras.

Requixa também salienta tal fato quando apresenta "os reflexos iniciais da industrialização e da urbanização sobre o tempo de trabalho e o tempo livre": “movimentos de natureza político-social e suas reivindicações de natureza trabalhista, repercutiram na criação e na ampliação do tempo livre” (REQUIXA 1977, p. 11).

Vários autores apontam a falta de reivindicação dos movimentos sociais por lazer. Para Stigger (1998, p. 86), uma das limitações para a construção das políticas de lazer é "a falta de mobilização popular". Segundo Isayama e Linhales (2006, p. 08), “a participação popular nas ações governamentais de esporte e lazer ainda é pequena".

Carvalho (2007), ao refletir sobre a trajetória da cidadania no Brasil, nos fala das reivindicações do movimento operário por férias e regulação da jornada de trabalho, mas o lazer também não aparece nesse trajeto.

Os operários lutavam também por uma legislação trabalhista que regulasse o horário de trabalho, o descanso semanal, as férias, e por direitos sociais como o seguro de acidentes de trabalho e aposentadoria. (CARVALHO, 2007, p. 60)

Quando investigou as três décadas iniciais do século XX, Marcassa afirma que:

[...] não se pode dizer que o lazer tenha sido uma conquista da classe trabalhadora como pensam alguns, pois quando das reivindicações do operariado brasileiro, o que se desejava era a definição da jornada em oito horas de trabalho e a consequente expansão do tempo livre. Portanto a conquista da classe trabalhadora organizada nesse período não foi o lazer, mas sim o tempo livre (MARCASSA, 2002, p. 188).

\footnotetext{
${ }^{9} \mathrm{O}$ tempo - assim como o espaço - é uma dimensão necessária à materialização do lazer.
} 
E, ainda hoje, apesar da aquisição pelo lazer de um lugar de destaque cada vez maior na sociedade brasileira ${ }^{10}$ - ele está presente na fala das pessoas, no discurso político, na mídia, no mercado, nas políticas sociais e no mundo acadêmico, sendo tema de grupos de pesquisa das mais diversas áreas do conhecimento (Educação Física, Antropologia, Psicologia, Comunicação Social, Economia, Turismo, Estudos Culturais, dentre outras) -, ele ainda ocupa um lugar desprivilegiado na escala de necessidades dos cidadãos, pois, "quando se pergunta às pessoas qual a importância do lazer nas suas vidas, a resposta fica entre sétimo a décimo lugar numa escala de prioridade" (MARCELLINO, 2006, p. 74).

Assim, o lazer no Brasil ocupa uma "posição secundária frente a outras esferas da vida social como a educação, a saúde, a moradia, o saneamento" (ISAYAMA e LINHALES, 2006, p.08). Segundo Requixa (1977, p.95), "não há dúvida quanto às reações negativas relativas ao estudo do lazer, num país subdesenvolvido, com problemas de desemprego e de subemprego", o que ainda hoje é perceptível.

Além disso, o lazer é, historicamente, um tema não muito valorizado por outros e diferentes motivos, como, por exemplo, os apresentados por Magnani (1996), quando relata a realização de sua pesquisa entre 1978 e 1980, que tinha como tema o lazer:

[...] foi preciso argumentar em favor de sua pertinência: afinal de contas tratava-se de uma atividade pouco valorizada porque, pensavase, está nas antípodas daquilo que se considera o lugar canônico da formação da consciência de classe e, além de ocupar uma parte mínima do tempo do trabalhador, não apresenta implicações políticas explícitas. (MAGNANI, 1996, p. 30).

Segundo Magnani (1984), as objeções mais correntes às pesquisas que tinham como tema o lazer eram:

${ }^{10}$ Cf. GOMES e MELO (2003); MELO e ALVES JUNIOR (2003); REQUIXA (1977); SANT’ANNA, 1994. 
[...] é considerado irrelevante, enquanto tema de pesquisa: há coisas mais "sérias" como o trabalho e a política; Aliás, nem mesmo existe: no caso específico dos trabalhadores, há quem constate que o tempo livre é basicamente utilizado para complementar os magros orçamentos doméstico; quando existe, ressente-se da falta de espaço, equipamentos, ou então [...] não passa de válvula de escape $\mathrm{e}$ alienação; (MAGNANI, 1984, p. 11).

Ou, como disse Bruhns, em 2002, o lazer não é valorizado "no âmbito acadêmico por não ser considerado relevante para a compreensão das sociedades e das relações humanas" (p. 07).

Assim, nas três últimas décadas, pelo menos, diferentes estudiosos vêm nos trazendo vestígios históricos que apontam na mesma direção, no que se refere ao lugar desprivilegiado ocupado pelo lazer na sociedade brasileira, apesar dos inegáveis avanços que vêm sendo construídos e que têm provocado um deslocamento desse lugar.

Por tudo isso, podemos constatar a existência de um todo contraditório em torno da constituição do lazer como direito social no Brasil, pois, aparentemente, ele não se constituiu como objeto de disputas e conflitos, não foi demandado por movimentos sociais nem reconhecido pela sociedade brasileira como tema que merecesse reflexão e, mesmo assim, se constituiu como direito social.

No entanto, é tarefa das mais fáceis justificar a presença do lazer como direito social na Constituição de 1988 a partir de concepções normativas, pois ele possui como conteúdo a cultura, e toda prática de lazer é cultura, o que faz dele um bem social e, consequentemente, um direito social, já que essa é a natureza de tais direitos.

Como todos os cidadãos possuem o direito de acessar a riqueza social de seu país, a definição do lazer como direito social pode ser, assim, facilmente justificada, já que ele é parte dessa riqueza. As concepções normativas presentes na sociedade 
brasileira no momento da construção da Constituição de 1988, igualdade, justiça e participação, nortearam a construção da carta magna atualmente vigente - apesar da disputa presente na Assembléia Nacional Constituinte de 1987 entre esses e outros valores (FERNANDES, 2006) -, principalmente no que se refere aos direitos sociais, pois tais concepções fazem parte da natureza de tais direitos.

As pesquisas até aqui realizadas apontam que não houve demanda popular por lazer - ao menos com esse nome. Terão sido, então, o motivo da inclusão do lazer como direito social na Constituição de 1988 as concepções normativas reivindicadas pela população no momento de sua construção? Terão essas concepções levado os Constituintes a incluir o lazer na Carta Magna de 1988, já que elas o justificam? Ou essa inclusão é fruto de interesses e valores de outros, para além da população? Essas perguntas só poderão ser respondidas através do desenvolvimento de pesquisas que investiguem a trajetória política do lazer no Brasil, porque o processo de construção histórica de um direito social precisa ser explicado em sua especificidade, pois não existe um caminho único ou uma explicação generalizada para a transformação de um problema em direito social, e as reflexões de Rothstein (1998) sobre as concepções normativas podem contribuir para a elucidação de tal trajetória.

Atentar para as concepções normativas das instituições e de suas políticas pode nos ajudar também a compreender situações como essa: a prefeitura municipal de Belo Horizonte possui, em sua estrutura organizacional administrativa, quatro órgãos que têm a "atribuição legal explícita"11 de desenvolver atividades de lazer. São elas: Secretaria Municipal Adjunta de Esportes (SMAES), Fundação de Parques Municipais (FPM), Fundação Municipal de Cultura (FMC) e Empresa Municipal de Turismo de Belo

${ }^{11}$ Munhoz, 2008, p.73 
Horizonte S/A (Belotur) ${ }^{12}$. Ao serem indagados sobre a existência de uma política pública de lazer em Belo Horizonte, os dirigentes de duas dessas secretarias afirmaram não existir uma política de lazer no município, enquanto os outros dois dirigentes afirmaram que tal política existe. Além disso, metade dos funcionários da FMC que foram entrevistados, não entende que as ações desenvolvidas por tal órgão se relacionam à promoção do lazer no município (MUNHOZ, 2008).

Por trás das respostas dadas pelos dirigentes das secretarias, existem concepções normativas que, se explicitadas, podem nos ajudar a compreender não apenas o motivo de tais respostas, mas também as políticas desenvolvidas por esses órgãos. Obviamente, as respostas foram norteadas por conceitos de política pública e de lazer, e pelo entendimento que os dirigentes possuem desses conceitos. Mas essas respostas foram norteadas também por valores. A escolha dos conceitos com os quais operamos se dá através de nossas concepções normativas. $\mathrm{O}$ entendimento dos dirigentes de que não existe uma política de lazer em Belo Horizonte pode estar balizado por uma concepção de justiça, pois os projetos desenvolvidos em tal município possuem abrangência limitada, quantidade insuficiente de equipamentos frente à demanda e não possuem continuidade (MUNHOZ, 2008), o que faz com que o lazer não possa ser acessado por todos os munícipes. Desse modo, como as políticas de lazer desenvolvidas em Belo Horizonte não são para todos, elas podem não ser consideradas como uma política pública de acordo com certa concepção de justiça.

A FMC, órgão que foi identificado pela pesquisa de Munhoz (2008) como promotor de ações de lazer contínuas ${ }^{13}$ e eventuais, não entende que desenvolve ações de lazer no município, não entende que é responsável pela política de lazer de Belo

\footnotetext{
${ }^{12}$ Conforme pesquisa realizada por Virna Munhoz (2008).

${ }^{13}$ A continuidade das ações é uma das características das políticas públicas.
} 
Horizonte ao lado de outras instituições municipais, apesar de possuir como objeto de suas ações a cultura. Mais uma vez há um conceito orientando tal entendimento, o de lazer, mas há também um conjunto de valores. O lazer é historicamente tido como algo menor, menos importante, ligado à falta de compromisso e de reflexão e ocupa uma posição secundária na vida das pessoas - ao menos quando nos atemos a esse signo linguístico, mas, se nos ativermos aos significados do que as pessoas fazem, podemos obter outra compreensão. Então, como considerar e admitir que um trabalho tão sério e comprometido, como o desenvolvido pela FMC, que tem como objeto a cultura, é uma ação de promoção do lazer? Assim, o mapa mental - que são as normas sociais - dos funcionários da FMC pode os estar levando a afirmar que suas ações não estão ligadas à promoção do lazer, pois desse modo eles garantem maior respeito e legitimidade para o trabalho desenvolvido por tal órgão.

As concepções normativas são, como nos diz Rothstein (1998), construídas socialmente e localizadas historicamente, não são as mesmas para todos e em todos os lugares, nem mesmo em um mesmo país, ainda que num mesmo período de tempo. Assim, cada instituição precisa ser estudada desde sua origem, para que possamos compreender as normas sociais que elas geram em cada momento e, assim, o comportamento das pessoas e as políticas públicas que elas desenvolvem.

\section{REFERÊNCIAS}

ARRETCHE, Marta. Emergência e Desenvolvimento do Welfare State: Teorias Explicativas. Rio de Janeiro, Revista Brasileira de Informação Bibliográfica em Ciências Sociais, , v. 39, p. 3-40, 1995. 
BRASIL. Constituição da República Federativa do Brasil: Texto constitucional promulgado em 05 de outubro de 1988, com alterações adotadas pelas Emendas Constitucionais de Revisão nos $1 / 92$ a 56/2007 e pelas Emendas Constitucionais de revisão no 1 a 6/94. Brasília: Senado Federal, Subsecretaria de Edições Técnicas, 2008.

BRUNHS, Heloísa T. Lazer e ciências sociais: diálogos pertinentes. São Paulo: Chronos, 2002.

CARVAlHO, José Murilo de. Cidadania no Brasil: o longo caminho. 9. ed. Rio de Janeiro: Civilização Brasileira, 2007.

COIMBRA, Marcos Antônio. Abordagens teóricas ao estudo das políticas sociais. In: ABRANCHES, S.H. et al. Política social e combate à pobreza. Rio de Janeiro: Jorge Zahar, 1987.

FARIA, Carlos Aurélio Pimenta de. Uma genealogia das teorias e modelos do Estado de Bem-Estar Social. In: DELGADO, M. G; PORTO, L. V. O estudo do bem-estar social no século XXI. São Paulo: LTR, 2007.

FERNANDES, Florestan. Pensamento e ação: o PT e os rumos do socialismo. 2. ed. São Paulo: Globo, 2006.

GOMES, Christianne Luce; MELO, Victor Andrade de. Lazer no Brasil: Trajetória de estudos, possibilidades de pesquisa. Porto Alegre, Movimento, n.19, 2003.

ISAYAMA, H. F; LINHALES, M. A. Apresentação. In: ISAYAMA, H. F; LINHALES, M. A. (Org.). Sobre lazer e política: maneiras de ver, maneiras de fazer. Belo Horizonte: Editora UFMG, 2006.

LINHALES, Meily Assbú. São as políticas públicas para a educação física/ esportes e lazer, efetivamente políticas sociais? Florianópolis, Motrivivência, v.10, n.11, p. 71-81, julho, 1998.

MAGNANI, José Guilherme. Quando o campo é a cidade: fazendo antropologia na metrópole. In: MAGNANI, José Guilherme; TORRES, Lillian L. (Org). Na metrópole: textos de antropologia urbana. São Paulo: EDUSP/FAPESP, 1996.

1984.

. Festa no pedaço: cultura popular e lazer na cidade. São Paulo: Brasiliense,

MANN. Michael. Las fuentes del poder social, I: uma historia del poder desde los comienzos hasta 1760 d. C. Madrid: Alianza Editorial, 1991.

. The sources of social power: the rise of classes and nation-states, $1760-$ 1914. Cambridge University Press, 1993, v. 2.

MARCASSA, Luciana. A invenção do lazer: educação, cultura e tempo livre na cidade de São Paulo (1888 - 1935). 2002. 204 f. Dissertação (Mestrado em Educação) Faculdade de Educação, Universidade Federal de Goiás, Goiânia, 2002. 
MARCELLINO, Nelson Carvalho. O lazer e os espaços na cidade. In: ISAYAMA, H. F; LINHALES, M. A. (Org.). Sobre lazer e política: maneiras de ver, maneiras de fazer. Belo Horizonte: Editora UFMG, 2006.

MELO, Victor Andrade de; ALVES JUNIOR, Edmundo de Drummond. Introdução ao lazer. Barueri: Manole, 2003.

MENICUCCI, Telma. Políticas públicas de lazer: questões analíticas e desafios políticos. In: ISAYAMA, H. F; LINHALES, M. A. (Org.). Sobre lazer e política: maneiras de ver, maneiras de fazer. Belo Horizonte: Editora UFMG, 2006.

MUNHOZ, Virna. O lazer como direito social na prefeitura de Belo Horizonte. In: Avaliação de políticas e políticas de avaliação: questões para o esporte e o lazer. Belo Horizonte: UFMG, 2008.

PEIXOTO, Elza. Levantamento do estado da arte nos estudos do lazer: (Brasil) séculos XX e XXI - alguns apontamentos. Educação e Sociedade, Campinas, v. 28, n. 99, p. 561-586, maio/ago, 2007.

REQUIXA, Renato. O lazer no Brasil. São Paulo: Brasiliense, 1977.

ROTHSTEIN, Bo. Just Institutions Matter: the Moral and Political Logic of the Universal Welfare State. Cambridge University Press, 1998.

RUA, Maria das Graças. Análise de políticas públicas: conceitos básicos, In: RUA, Maria das Graças; CARVALHO, Maria Izabel Valadão de (Org.). O Estudo da Política: Tópicos Selecionados. Brasília: Paralelo 15, 1998.

SANT'ANNA, Denise Bernuzi. O prazer justificado: história e lazer (São Paulo, 1969/1979). São Paulo: Marco Zero, 1994.

SIMAN, Angela Maria. Políticas públicas: a implementação como objeto de reflexão teórica e como desafio prático. 2005. 300 f. Tese (Doutorado em Ciência Política) Faculdade de Filosofia e Ciências Humanas, Universidade Federal de Minas Gerais, Belo Horizonte, 2005.

STIGGER, Marco Paulo. Políticas sociais em lazer, esportes e participação: uma questão de acesso e de poder ou subsídios para tomar uma posição frente à pergunta.... Santa Catarina, Motrivivência, v.10, n. 11, p.83-96, 1988.

VERONEZ, Luiz Fernando Camargo. Quando o Estado joga a favor do Privado: as políticas de Esporte após a Constituição de 1988. 2005. 386 f. Tese (Doutorado em Educação Física) - Faculdade de Educação Física, Unicamp, Campinas, 2005.

VIEIRA, Liszt. Cidadania global e Estado nacional. Dados, Rio de Janeiro, v.42, n.3, p.01-17, 1999. 


\section{Endereço da autora:}

Flávia da Cruz Santos

Rua Teresa Bonato Signori, 31,

Jardim Santa Genebra II, Campinas, SP

CEP 13084-777

Endereço eletrônico: csantosflavia@yahoo.com.br 